\title{
AN ON-LINE OPTIMAL ARTIFICIAL NEURAL NETWORK-BASED CONTROLLER FOR SIMPLIFIED ORDER POWER SYSTEMS
}

\author{
El-Nobi A. Ibrahim ; Ali. M. Youssef and M. Abdel-Hakim \\ Electrical Engineering Department, Faculty of Engineering, Assiut \\ University, Assiut, Egypt
}

(Received September 1, 2005 Accepted October 22, 2005)

The paper presents an on-line optimal artificial neural network (ANN)- based controller for simplified order power systems to improve the dynamic response under different operating conditions. The original $13^{\text {th }}$ order power system is reduced to $5^{\text {th }}$ order model. The basic feature of the proposed ANN controller is that it consists of two neural networks, one of them (ANN1) maps the optimal control process at different loading conditions and the other (ANN2) maps the feedback control to produce the required control action signal. The ANN1 is trained using input/output pairs of data which are collected from the optimal control of the reduced order model of power system at different loading conditions The ANN2 parameters are adapted on-line through the ANNI according to loading conditions. The digital simulation results proved the high performance of the synchronous generator using the proposed ANN controller in terms of fast response and less undershot/overshot under different operating conditions. A comparison between the off-line fixed parameters optimal controller and the proposed ANN controller validates the effectiveness and reliability of the ANN controller.

KEYWORD: Reduction Technique, power systems, optimal controller, ANN controller.

\section{NOMENCLATURE}

q-axis reactance

d-axis reactance

q-axis mutual reactance

d-axis mutual reactance

q-axis damper winding reactance

d-axis damper winding reactance

Field winding reactance

Transmission lines reactance

Transmission lines resistance

Inertia constant

Steady state speed governer regulation

Governer time constant 


$\begin{array}{ll}\mathrm{T}_{\mathrm{t}} & \text { Steam turbine time constant } \\ \mathrm{K}_{\mathrm{e}} & \text { Exciter gain } \\ \mathrm{K}_{\mathrm{a}} & \text { Amplifier gain } \\ \mathrm{K}_{\mathrm{r}} & \text { AVR gain } \\ \mathrm{K}_{\mathrm{s}} & \text { Exciter stablizer gain } \\ \mathrm{T}_{\mathrm{e}} & \text { Exciter time constant } \\ \mathrm{T}_{\mathrm{a}} & \text { Amplifier time constant } \\ \mathrm{T}_{\mathrm{r}} & \text { AVR time constant } \\ \mathrm{T}_{\mathrm{s}} & \text { Exciter stablizer time constant }\end{array}$

\section{INTRODUCTION}

Power systems are continuously increasing in size in national and international levels. Inter-connected unified networks are installed in nearly all countries and continent. Consumers demand of electricity increases day after day allover the world. Stable operation of such large power systems is a necessity for all people. Power systems are usually subjected to continual impacts due to lines and loads switching and different types of faults due to malfunctions of utility drives or failures at consumer's networks or loads. According to these interconnections, the systems orders become relatively high and the complexity is increased. Therefore, the analysis of dynamic stability and controller's design of these large interconnected power systems becomes time consuming and laborious in order to have an accordance order representation of high-order power systems, model reduction techniques are used for getting simplified models with adequate accordance. Several methods for model reduction are based on eigenvalue analysis of the system linearized differential equations [1,2]. Davison [1] had used the eigenvalues and eigenvectors of the complete system model to compute a reduced model of smaller order than the original. In this method, the dominant eigenvalues are to be chosen with real parts closest to the imaginary axis.

Transient stability is of main concern to power systems engineers, as its loss can lead to dangerous electromechanical oscillations or to partial or complete blackouts. Damage of synchronous generators shafts can also occur. Preservation of such transient stability is assured by the presence of capable and effective controls. An additional signal to the excitation and /or mechanical system is currently being used for improving the damping characteristic of the synchronous generator under disturbance conditions. The classical controllers with filters fed from speed signals are well known and used in practice [3]. Modern optimal control theory has now been used in this field $[4,5]$. Normally, the parameters of optimal controller are designed at certain operating point to give a good performance. However, the system dynamic response may deteriorate when operating point changes.

The artificial intelligent neural network (ANN) has been developed for improving systems dynamic performance and to adapt controller parameters in real time due to any change in the loading conditions [6-12]. Dejan J. S. and Y. H. Pao, in 1989 used an ANN based to evaluate the critical clearing time of the power system [6]. An ANN based power system stabilizer (PSS) using an on-line measurements of the generator active output power and power factor as an input signals to the PSS is designed by Y. 
Y. Hsu and C. R. Chen in 1991 [7]. Y. Zhang, et al have presented an ANN based PSS. They concluded that PSS can provide good damping of the power system over a wide range of operating point and significantly improve the dynamic performance of the system [8]. ANN power system stabilizer based a pole placement state feedback gain as off-line training is presented be El-Sherbiny, et al [9]. They indicate the effectiveness of the proposed ANN controller in comparison with the conventional PI controller. An enhanced adaptive neural network control scheme, based on the adaptive linear element is designed by L. C. Min and L. Qing [10]. This schemeis applied to multi- machine system and it has effectiveness for different types of faults and for a wide range of operating point.

The present paper introduces an optimal ANN controller based on reduced order model of power system. This controller is constructed from two neural networks, one of them (ANN1) maps the optimal control process at different loading conditions and the other (ANN2) maps the feedback control to produce the required control action signal. The ANN2 parameters are adapted on-line through the ANN1 according to loading conditions and the reduction technique is used through the designing stage of such controller in order to retain only the states which are usually observable. The ANN1 is trained using input/output pairs of data which are collected from the optimal control of the reduced order model of power system at different loading conditions.

\section{POWER SYSTEM MODEL}

The studied power system consists of a $13^{\text {th }}$ order model of a synchronous machine connected to an infinite bus through a transimission line as shown in Fig.1. This model contains of $5^{\text {th }}$ order for winding representation of synchronous machine, $4^{\text {th }}$ order for automatic voltage regulator (AVR)\& exciter and $4^{\text {th }}$ order for turbine \& governor.

The matrix form for the power system model

$$
\begin{aligned}
& x=A x+B u \\
& A_{1} x+\frac{1}{\omega_{b}} A_{2} x=B u
\end{aligned}
$$

From the above equations the A matrix can be written as

$$
A=-\omega_{b} A_{2}^{-1} A_{1}
$$

Elements of A-matrix are defined in appendix[a] where

$$
\begin{aligned}
x & =\left[\begin{array}{lllllllllllll}
\Delta i_{q} & \Delta i_{d} & \Delta i_{k q} & \Delta i_{k d} & \Delta i_{f} & \Delta \delta & \Delta \omega & \Delta E_{f d} & \Delta V_{a} & \Delta V_{r} & \Delta V_{s} & \Delta P_{m} & \Delta P_{g}
\end{array}\right]^{T} \\
u & =\left[\begin{array}{lll}
\Delta P_{L} & \Delta V_{c} & \Delta P_{c}
\end{array}\right]^{\mathrm{t}}
\end{aligned}
$$




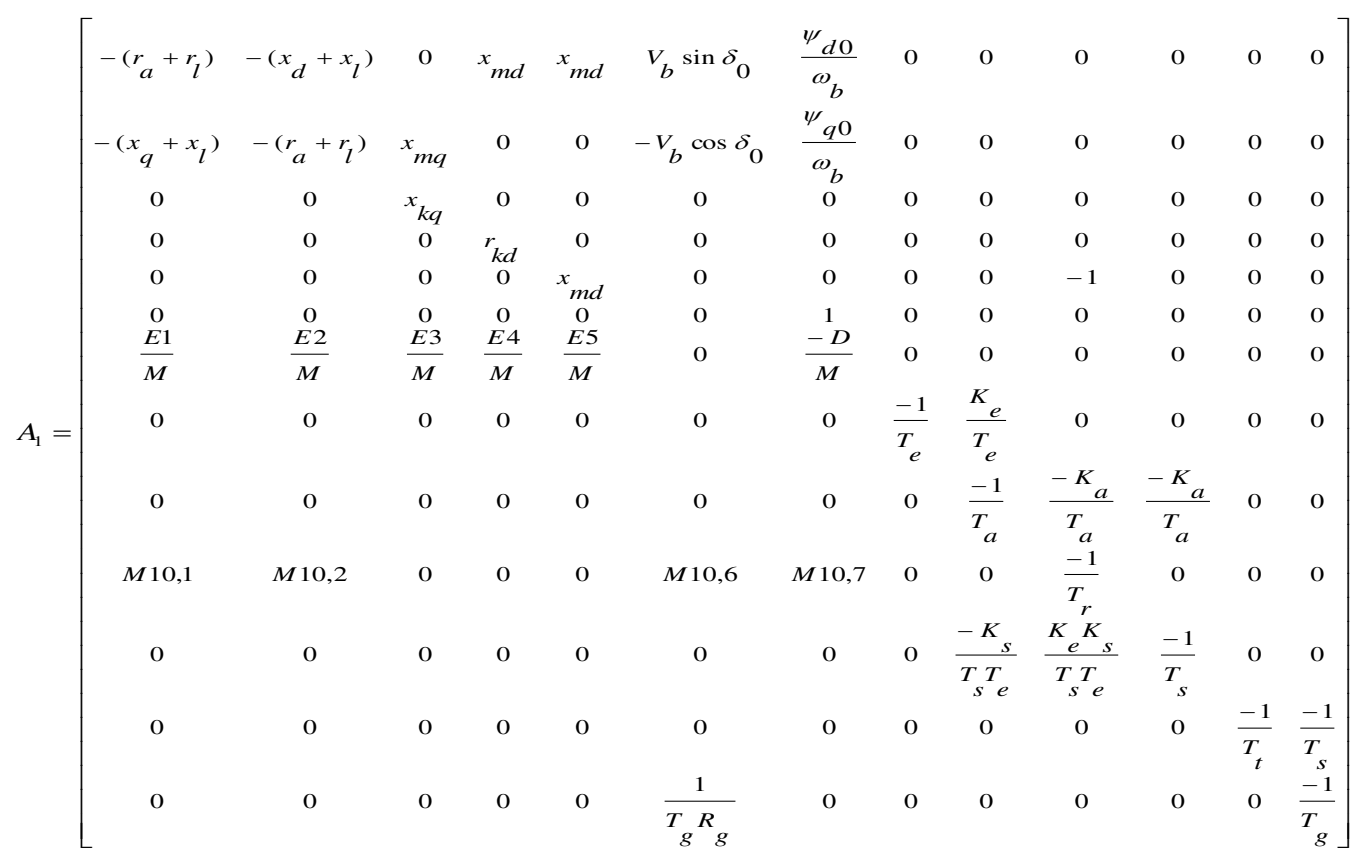

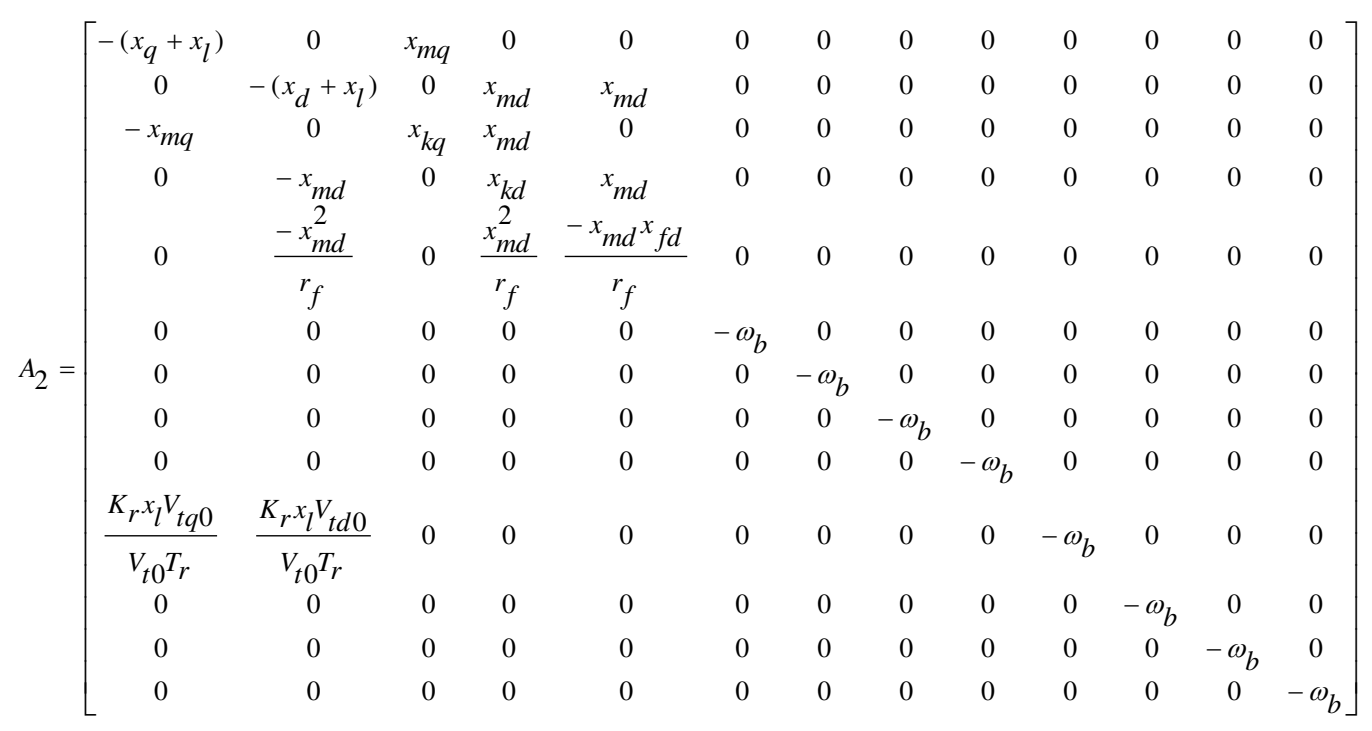

$B=\left[\begin{array}{ccccccccccccc}0 & 0 & 0 & 0 & 0 & 0 & \frac{1}{M} & 0 & 0 & 0 & 0 & 0 & 0 \\ 0 & 0 & 0 & 0 & 0 & 0 & 0 & 0 & \frac{K_{a}}{T_{a}} & 0 & 0 & 0 & 0 \\ 0 & 0 & 0 & 0 & 0 & 0 & 0 & 0 & 0 & 0 & 0 & 0 & \frac{1}{T_{g}}\end{array}\right]^{t}$ 


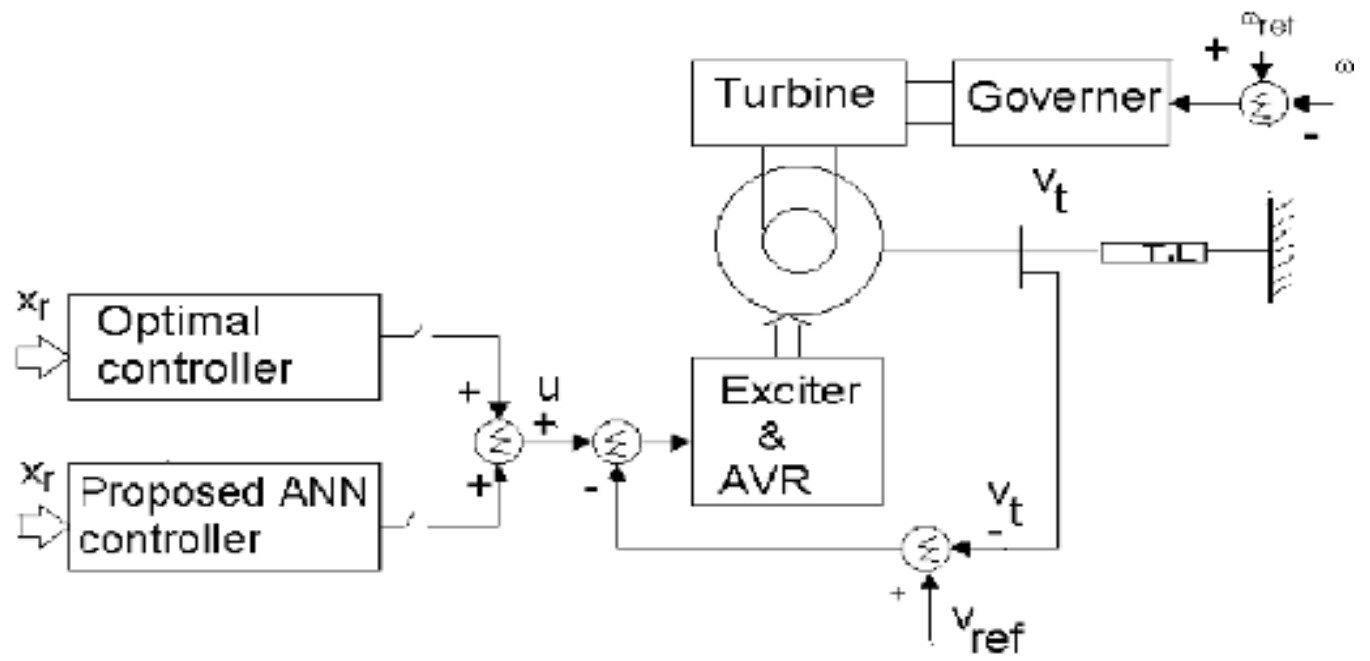

Fig. 1: Schematic diagram of power system Model.

\section{REDUCTION TECHNIQUE}

The methods of reducing dynamic system are discussed in [3:6]. The differences between these methods are the way of choosing the dominant eigenvalues. The input output performance indices in [4,5] are used for giving good accuracies. Instead of choosing the eigenvalues closest to the Jw-axis, the eigenvalues which have highest input- output indices can be selected. After the dominant eigenvalues are chosen, the Davision method [3] is used for giving the reduced order model of power system. The model reduction technique is used for reducing a $13^{\text {th }}$ order model for generating unit to $5^{\text {th }}$ order model which is used for controller design. The retained states considered are the rotor angle, the rotor frequency, the exciter voltage and stator current components which are measured for achieving control action.

The A matrix of the system which is given by Eq.(1) can be rewritten as follows:

$A=M \Lambda M^{-1}$

where;

$M$ is the matrix of eigenvectors

$\Lambda$ is the diagonal matrix of eignvalues

The reduced system model is described by following equation

$$
\dot{x}_{r}=A_{r} x_{r}+B_{r} u
$$

where

$$
\begin{aligned}
& A_{r}=M_{r} \Lambda_{r} M_{r}^{-1} \\
& B_{r}=M_{r}\left[M^{-1} B\right]^{*}
\end{aligned}
$$

$A_{r} \& B_{r} \quad$ are reduced order constant system matrices. 
$x_{\mathrm{r}} \quad$ is the retained states vector

$M_{r} \quad$ is a matrix representing a subset of the complete eigenvector matrix $M$. The rows of this matrix are selected from $M$ based on retained states, the columns of $M_{r}$ are selected from $M$ based on retained eignvalues

$\Lambda_{r} \quad$ is a diagonal matrix of retained eignvalues.

$\left[M^{-1} B\right]^{*}$ is a diagonal matrix consisting of the retained rows of $M^{-1} B$ corresponding to $x_{\mathrm{r}}$.

\section{THE OPTIMAL CONTROLLER DESIGN PROCEDURE}

the object of the optimal control design is determining the optimal control law $u(t, x)$ which can transfer system from its initial state to the final state such that a given quadratic performance index is minimized. Considering the reduced order model of power system which is described by Eq. (5). The quadratic performance index $\mathrm{J}$ is described by:

$$
J=\int\left(x_{r}{ }^{t} Q x_{r}+u^{t} R u\right) d t
$$

the optimal control law is written as

$$
u(t)=K_{r} x_{r}(t)
$$

where: $\mathrm{Q}$ is positive semi definite matrix and $\mathrm{R}$ is real symmetrical matrix. The problem is to find the vector $K_{r}$ of control law

The problem then is to choose $K r$ to minimize the performance index $\mathrm{J}$.This problem is discussed in Ref [4] and the $K r$ is given by:

$$
K_{r}=-R^{-1} B_{r}^{T} P
$$

The matrix $P$ is positive definite, symmetric solution to the matrix Ricciti equation which is written as:

$$
P A_{r}+A_{r}^{T} P+Q-P B_{r} R^{-1} B_{r}^{T} P=0
$$

Normally the parameters of optimal controller are designed at nominal operating point to give a good performance.

\section{OPTIMAL ARTIFICIAL NEURAL NETWORK}

Optimal ANN controller based on reduced order model of power system is introduced. This controller is constructed from two neural networks as shown in Fig. 3 , one of them (ANN1) maps the optimal control process at different loading conditions and the other $(A N N 2)$ maps the feedback control $(\mathrm{u}(\mathrm{t})=\mathrm{kx}(\mathrm{t}))$ to produce the control signal. The ANN2 parameter adapts online through the ANN1 according to loading conditions and the reduction technique is used through the designing stage of such controller in order to retain only the states which are measured (observable states),reduce the consuming time and reduce the neurons which are required for controller structure. The first ANN1 is trained using the input output pairs of data which are collected from the optimal control of the reduced order model of power 
system at different loading condition. The ANN1 have 2 input nodes [P, Q] and 4-nodes in hidden layer and also 5-nodes in the output layer. The output of the ANN1 is the weights of ANN2.

The ANN2 contains the 5 nodes in input layer [the five interesting states] and one node in output layer [control signal]

\subsection{The Operation Steps of a ANN1}

Step 1: Nodes of the input layer receive signals from the loading condition, the input vector is $\mathrm{Pq}$

$$
P q=[P ; Q]
$$

Step 2: Output of the input layer passes to hidden nodes through the weighted links, the resulting weight matrix between the hidden and input neurons is given by w11 and the hidden nodes biases are given by the b11.

Step 3: The output of hidden nodes results from input signal passing through the activation function (tan sigmoid transfer function), the hidden layer output vector of ANN1 is oh,where

$$
o h=\operatorname{tansig}(w 11 * P q, b 11)
$$

Step 4: Hidden layer outputs sent to the output nodes through weighted links, the resulting weight matrix between the hidden and output neurons is given by w21 and the hidden nodes biases given by the b21.

Step 5: The ANN1 output is obtained using another activation function (Linear transfer function ), the output vector of ANN1 is o1, where

$$
\text { o1=purelin (w21*oh, b21) }
$$

\subsection{The Operation Steps of a ANN2}

The following steps describe the operation of a ANN2

Step 1: Nodes of the input layer receive signals from the outside world, the input vector is $X \mathrm{r}$

$$
X r=\left[\Delta \delta ; \Delta \omega ; \Delta E f d ; \Delta i_{q} ; \Delta i_{d}\right]
$$

Step 2: Output of the input layer passes to output node through the weighted links, the weight matrix between the input and output neuron is given by $\mathrm{w} 2$.

$$
w 2=o 1
$$

$\mathrm{o} 1$ is the output vector of ANN1 is described by equations (12:14).

Step 3:_The ANN1 output is obtained using activation function (Linear transfer function ), the output of ANN2 is control signal (u)

$$
u=\text { purelin }(w 2 * X r, b 2)
$$

The equations from 12 to 17 describe the operation of the proposed artificial neural network controller. The ability of this controller to adapt its parameters with itself dependS on the loading conditions. The closed loop matrix of system with ANN can be calculated as:

$$
\mathrm{A}_{\mathrm{ANN}}=\mathrm{A}_{\mathrm{r}}-\mathrm{B}_{\mathrm{r}} * \mathrm{w} 2
$$




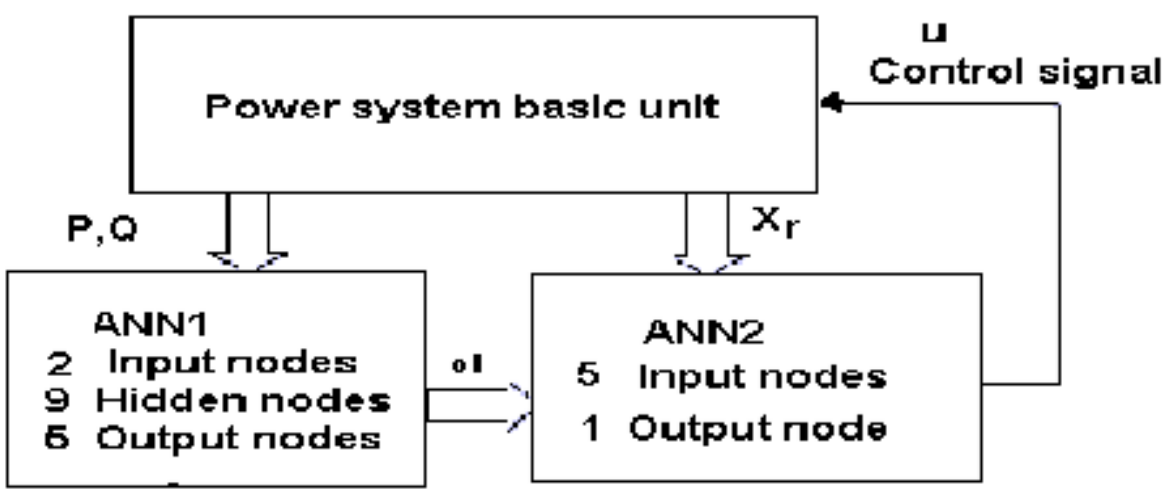

Fig. 2: Block diagram of the proposed controller.

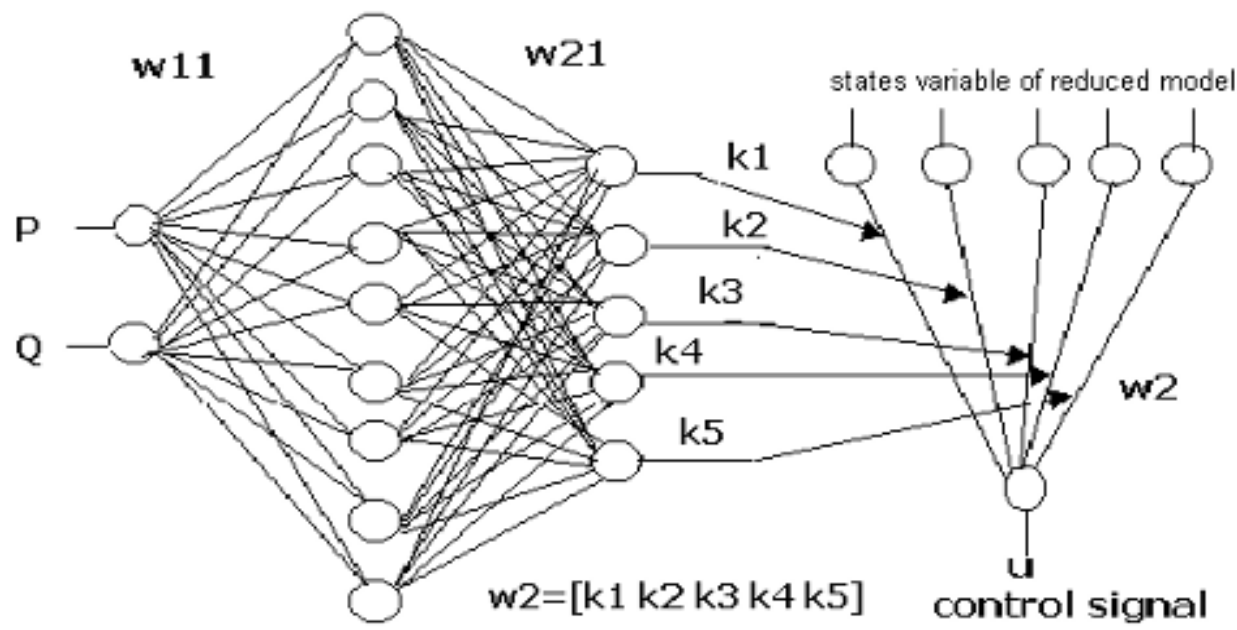

ANN1

ANN2

Fig. 3: ANN Structure.

\section{DIGITAL SIMULATION RESULT}

The power system shown in Fig. 1 is used for digital simulation. It consists of a synchronous machine connected to an infinite bus through a transimission line. The complete data of this system are given in appendix (b). The model reduction technique is given in [2], which is used for reducing the $13^{\text {th }}$ order model of generating unit (A,B in Eqn.1) to $5^{\text {th }}$ order model $\left(A, B_{r}\right.$ in Eqn.5). At nominal operating point $\mathrm{P}=.75, \mathrm{Q}=0.0$ and the reduced order models is calculated as follows: 


$$
\begin{aligned}
& A_{r}=\left[\begin{array}{ccccc}
0 & 1 & 0 & 0 & 0 \\
-1.6843 & 0.144 & 0.61356 & -96.677 & -56.46 \\
11.499 & 1.1557 & -0.68237 & -22.348 & 0.94102 \\
6.5536 & 2.0122 & 0.042102 & -19.098 & 0.15544 \\
0.074332 & 2.1151 & 0.59603 & 0.086713 & -1.6279
\end{array}\right] \\
& B_{r}=\left[\begin{array}{ccc}
-0.017014 & 0.089148 & -0.72744 \\
71.631 & 7.3419 & -1.0961 \\
-0.92436 & 11.909 & -4.1655 \\
9.521 & -0.53664 & 0.95514 \\
0.22388 & 0.84646 & 0.13895
\end{array}\right]
\end{aligned}
$$

Table 1 gives the eigenvalues of both the original and reduced order models and the corresponding time response is dedicated in Fig. 4.

\begin{tabular}{|c|c|}
\hline $\begin{array}{c}\text { Eigenvalues of } 13^{\text {th }} \\
\text { order model }\end{array}$ & $\begin{array}{c}\text { Eigenvalues of } 5^{\text {th }} \text { order } \\
\text { model }\end{array}$ \\
\hline $\begin{array}{lc}-1000 & \\
-26.935+ & 376.49 \mathrm{i} \\
-26.935- & 376.49 \mathrm{i} \\
-26.245+ & 39.868 \mathrm{i} \\
-26.245- & 39.868 \mathrm{i} \\
-38.227 & \\
-3.5219+ & 15.251 \mathrm{i} \\
-3.5219- & 15.251 \mathrm{i} \\
-13.371 & \\
-4.1084 & \\
-0.42476+ & 0.86163 \mathrm{i} \\
-0.42476- & 0.86163 \mathrm{i} \\
-0.97768 & \end{array}$ & $\begin{array}{l}-3.5219+15.2508 \mathrm{i} \\
-3.5219-15.2508 \mathrm{i} \\
-13.3713 \\
-0.4248+0.8616 \mathrm{i} \\
-0.4248-0.8616 \mathrm{i}\end{array}$ \\
\hline
\end{tabular}

Table 1 : The eigenvalues of the original and reduced power system models.

From the digital simulation results shown in Fig. 4 it can be seen that the $5^{\text {th }}$ order model give a good accuracies. The optimal controller is designed in section 3 , the feedback matrix is calculated by using Eq. (10) at nominal operating point $(\mathrm{P}=0.75 \mathrm{pu}$ $\mathrm{Q}=0.0 \mathrm{pu}$ ) to minimize the performance index $\mathrm{J}$ in Eq. (8)

$K_{r}=\left[\begin{array}{lllll}-1.2584 & 0.5948 & -0.6375 & -8.2231 & -10.9569\end{array}\right]$

Using this matrix the closed loop eigenvalues of system with optimal controller are calculated at different operating conditions and the results are tabulated in table 2.

The proposed ANN controller is constructed from two neural networks, this is discussed in section (5). The ANN1 is trained using input/output pairs of data which are collected from the optimal control of the reduced order model of power system at different loading conditions. The training data was fed to Matlab Tool Box to calculate the weights and biases of ANN1 
The statistical data for ANN1 training

No of iteration $=10000$

Max. squared error $=1 \mathrm{E}-3$

Learning rate $=.001$

The resulting weight matrix between the hidden and input neurons, and also the hidden nodes biases matrix are given by

$$
\mathrm{b} 11=\left[\begin{array}{c}
-2.1918 \\
-2.3053 \\
-7.2796 \\
7.22 \\
23.759 \\
23.532 \\
77.5 \\
1.2978 \\
1.5152
\end{array}\right] \quad \mathrm{w} 11=\left[\begin{array}{cc}
1.9432 & 0.091295 \\
2.0553 & -0.0047312 \\
1.9152 & -12.154 \\
-1.8667 & 12.126 \\
-74.947 & 30.473 \\
-74.367 & 30.127 \\
-1.1156 & 128.77 \\
3.2499 & 1.9344 \\
-1.2181 & 1.7187
\end{array}\right]^{t}
$$

The resulting weight matrix between the output and hidden neurons, and also the output nodes biases matrix are given by

$$
\mathrm{w} 21=\left[\begin{array}{ccccc}
-14.991 & 1.969 & 1.7769 & -7.8039 & -22.269 \\
13.698 & -1.7419 & -1.6922 & 9.1325 & 20.749 \\
-84.972 & -8.1071 & -0.50802 & 69.043 & 47.282 \\
-85.607 & -8.2762 & -0.5069 & 68.909 & 47.566 \\
-5.2901 & 3.2394 & 0.92924 & -9.5876 & 56.63 \\
5.7097 & -3.2119 & -0.75665 & 9.898 & -56.783 \\
8.0854 & 0.54458 & .0014447 & -8.9805 & 0.87331 \\
4.1223 & 0.36252 & 0.29057 & -0.74039 & -2.8098 \\
-4.1207 & -0.068004 & -0.11298 & 1.423 & 2.5943
\end{array}\right]^{t} \mathrm{~b} 21=\left[\begin{array}{c}
-9.3186 \\
-0.49551 \\
-0.71995 \\
8.9751 \\
-4.725
\end{array}\right]
$$

The ANN2 parameters are adapted on-line through the ANN1 according to loading conditions. The closed loop eigenvalues of system with proposed ANN controller are calculated at different operating condition by using Eq.18. The results of system with proposed ANN, with optimal controller and without controller are tabulated in Table 2.

To validate the above results, time responses of speed deviation for $0.01 \mathrm{pu}$ increase in load power are drawn at a wide range of operating conditions. In each case the responses of the system with optimal controller and without controller are also given. Figures 5, 6, 7 and 9 show the rotor speed deviation response due to 0.01 load disturbance at lage power factor loads at different controller. Figures 8 and 10 show the rotor speed deviation response due to 0.01 load disturbance at lead power factor loads at different controller . 
It can be concluded from these results that the system with optimal controller give good dynamic response and the system with proposed ANN give responses better than the responses of the system with optimal controller. Figsures 8, 10 and 11 show the system without controller and with optimal controller suffers from synchronous instability in other hand the system with proposed ANN controller provide good dynamic response at the same operating conditions. The comparision of settling time between different controllers are given in table 3 .

Table 2: Eigenvalue at different controller and at different operating conditions of the reduced order model.

\begin{tabular}{|c|c|c|c|}
\hline $\begin{array}{l}\text { Load } \\
\text { condition }\end{array}$ & $\begin{array}{l}\text { System without } \\
\text { controller }\end{array}$ & $\begin{array}{c}\text { System with } \\
\text { optimal controller }\end{array}$ & $\begin{array}{l}\text { System } \\
\text { with proposed } \\
\text { ANN controller }\end{array}$ \\
\hline $\begin{array}{l}\mathrm{P}=0.75 \\
\mathrm{Q}=0.0\end{array}$ & $\begin{array}{l}-3.5219+15.2508 \mathrm{i} \\
-3.5219-15.2508 \mathrm{i} \\
-13.3713 \\
-0.4248+0.8616 \mathrm{i} \\
-0.4248-0.8616 \mathrm{i}\end{array}$ & $\begin{array}{l}-9.6721+15.2263 \mathrm{i} \\
-9.6721-15.2263 \mathrm{i} \\
-0.3119 \\
-11.7442+0.5954 \mathrm{i} \\
-11.7442-0.5954 \mathrm{i}\end{array}$ & $\begin{array}{l}-10.4165+15.3774 \mathrm{i} \\
-10.4165-15.3774 \mathrm{i} \\
-0.6208 \\
-7.7532 \\
-17.4330\end{array}$ \\
\hline $\begin{array}{l}\mathrm{P}=0.25 \\
\mathrm{Q}=0.0\end{array}$ & $\begin{array}{lc}-6.4568+ & 18.531 \mathrm{i} \\
-6.4568- & 18.531 \mathrm{i} \\
-7.1595 & \\
-0.5578+ & 0.3351 \mathrm{i} \\
-0.5578- & 0.3351 \mathrm{i} \\
\end{array}$ & $\begin{array}{lc}-6.4568+ & 18.531 \mathrm{i} \\
-6.4568- & 18.531 \mathrm{i} \\
-7.1595 & \\
-0.5578+ & 0.3351 \mathrm{i} \\
-0.5578- & 0.3351 \mathrm{i}\end{array}$ & $\begin{array}{lc}-9.4082+ & 18.28 \mathrm{i} \\
-9.4082- & 18.28 \mathrm{i} \\
-1.2219 & \\
-6.0768 & \\
-17.095 & \\
\end{array}$ \\
\hline $\begin{array}{l}\mathrm{P}=0.75 \\
\mathrm{Q}=0.6\end{array}$ & $\begin{array}{l}-14.6084 \\
-2.6732+13.2562 \mathrm{i} \\
-2.6732-13.2562 \mathrm{i} \\
-0.5075+0.4225 \mathrm{i} \\
-0.5075-0.4225 \mathrm{i} \\
\end{array}$ & $\begin{array}{l}-4.2354+10.7103 \mathrm{i} \\
-4.2354-10.7103 \mathrm{i} \\
-1.1834 \\
-16.8061+7.3942 \mathrm{i} \\
-16.8061-7.3942 \mathrm{i} \\
\end{array}$ & $\begin{array}{l}-1.2264 \\
-6.2935+10.8393 \mathrm{i} \\
-6.2935-10.8393 \mathrm{i} \\
-15.9735+4.3691 \mathrm{i} \\
-15.9735-4.3691 \mathrm{i} \\
\end{array}$ \\
\hline $\begin{array}{l}\mathrm{P}=0.75 \\
\mathrm{Q}=-0.6\end{array}$ & $\begin{array}{l}-19.5200 \\
0.2410+12.2945 \mathrm{i} \\
0.2410-12.2945 \mathrm{i} \\
0.7802 \\
-0.6056\end{array}$ & $\begin{array}{l}0.2414 \\
-3.8598+10.8910 \mathrm{i} \\
-3.8598-10.8910 \mathrm{i} \\
-26.7929 \\
-10.572\end{array}$ & $\begin{array}{l}-22.0042 \\
-8.6232+11.3263 \mathrm{i} \\
-8.6232-11.3263 \mathrm{i} \\
-0.5481 \\
-11.7625\end{array}$ \\
\hline $\begin{array}{l}\mathrm{P}=1.2 \\
\mathrm{Q}=0.6\end{array}$ & $\begin{array}{l}-19.1532 \\
-0.4137+12.4600 \mathrm{i} \\
-0.4137-12.4600 \mathrm{i} \\
-0.4443+0.7734 \mathrm{i} \\
-0.4443-0.7734 \mathrm{i}\end{array}$ & $\begin{array}{l}-18.3961+8.6234 \mathrm{i} \\
-18.3961-8.6234 \mathrm{i} \\
-2.6355+9.6792 \mathrm{i} \\
-2.6355-9.6792 \mathrm{i} \\
-0.6384\end{array}$ & $\begin{array}{l}-0.8057 \\
-6.5433+9.5543 \mathrm{i} \\
-6.5433-9.5543 \mathrm{i} \\
-16.7937+4.2975 \mathrm{i} \\
-16.7937-4.2975 \mathrm{i}\end{array}$ \\
\hline $\begin{array}{l}\mathrm{P}=1.2 \\
\mathrm{Q}=-0.6\end{array}$ & $\begin{array}{l}-20.0862 \\
0.6424+11.9901 \mathrm{i} \\
0.6424-11.9901 \mathrm{i} \\
1.1391 \\
-0.7657\end{array}$ & $\begin{array}{l}-27.4922 \\
-3.0553+10.5244 \mathrm{i} \\
-3.0553-10.5244 \mathrm{i} \\
0.1721 \\
-11.2971 \\
\end{array}$ & $\begin{array}{l}-24.7373 \\
-7.3560+10.4867 \mathrm{i} \\
-7.3560-10.4867 \mathrm{i} \\
-0.5163 \\
-13.9946\end{array}$ \\
\hline
\end{tabular}




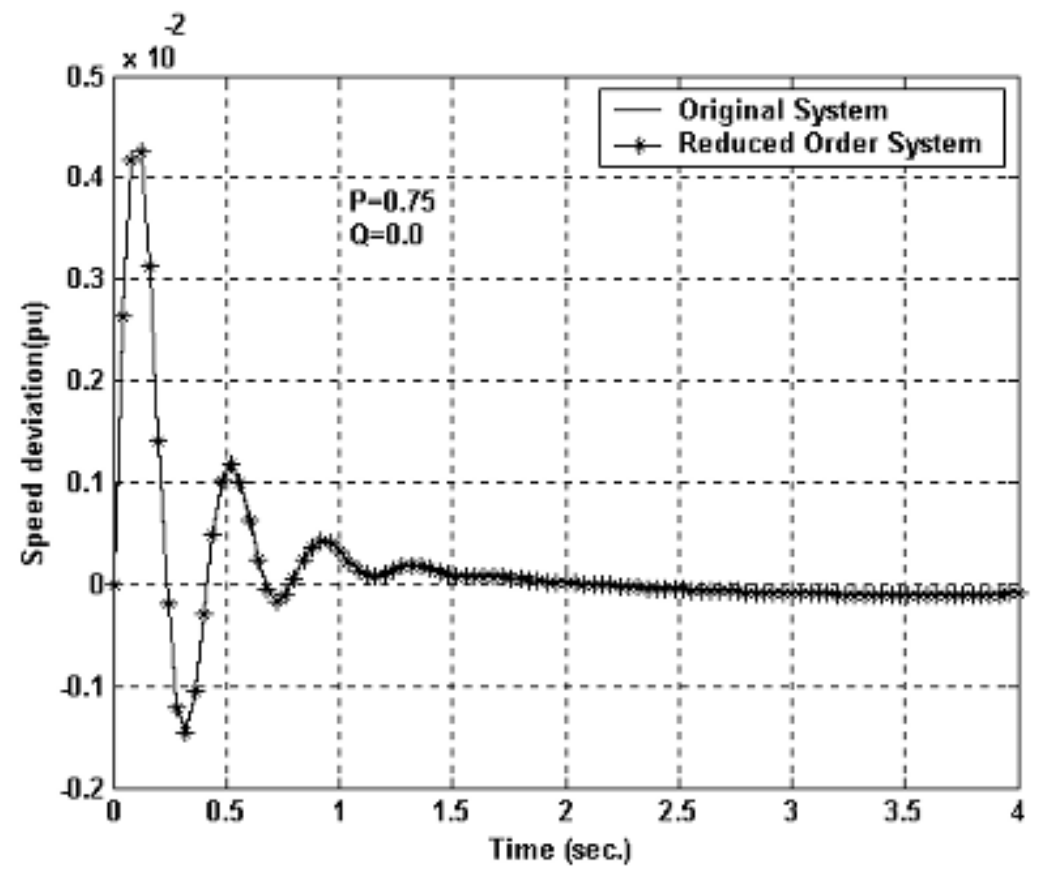

Fig. 4: Rotor speed deviation response due to $0.01 \mathrm{pu}$ load disturbance for original and reduced order model at loading condition ( $P=0.75 Q=0.0)$.

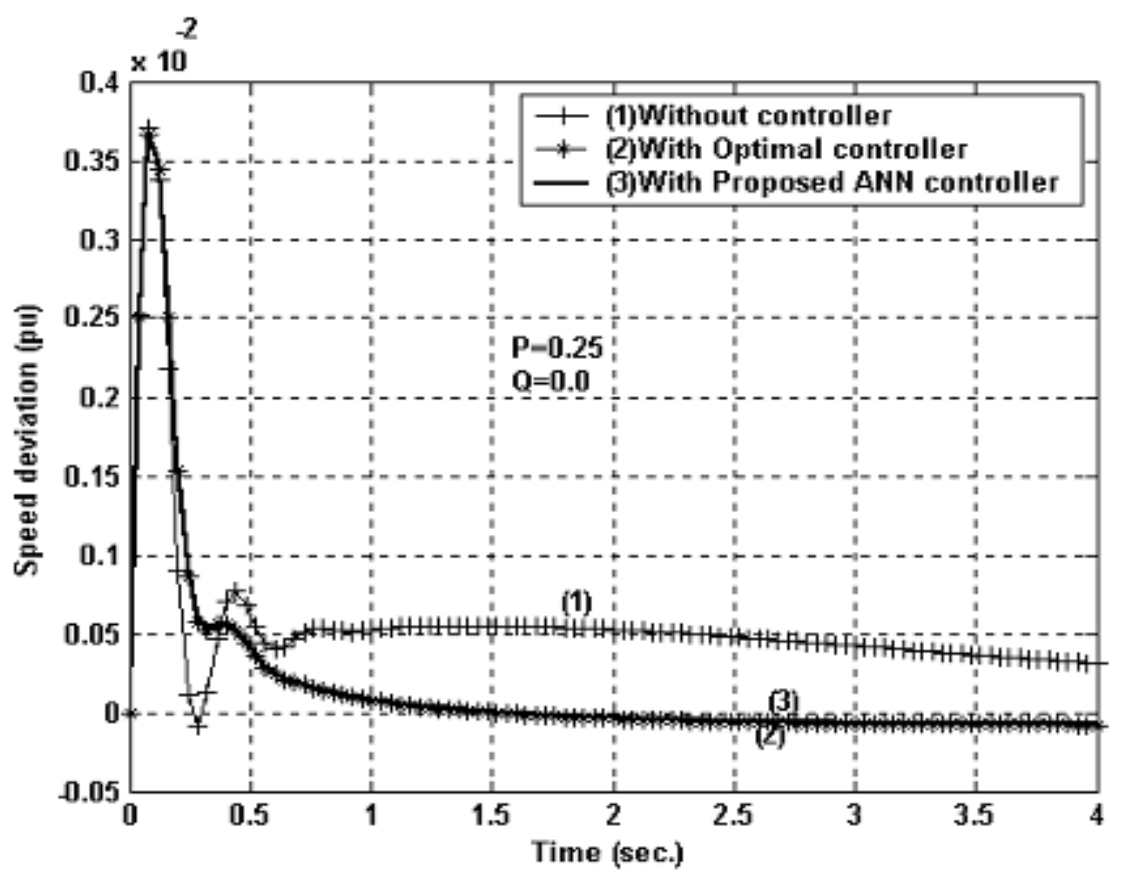

Fig. 5 : Rotor speed deviation response due to 0.01 pu load disturbance at loading condition ( $P=0.25 Q=0.0$ ). 


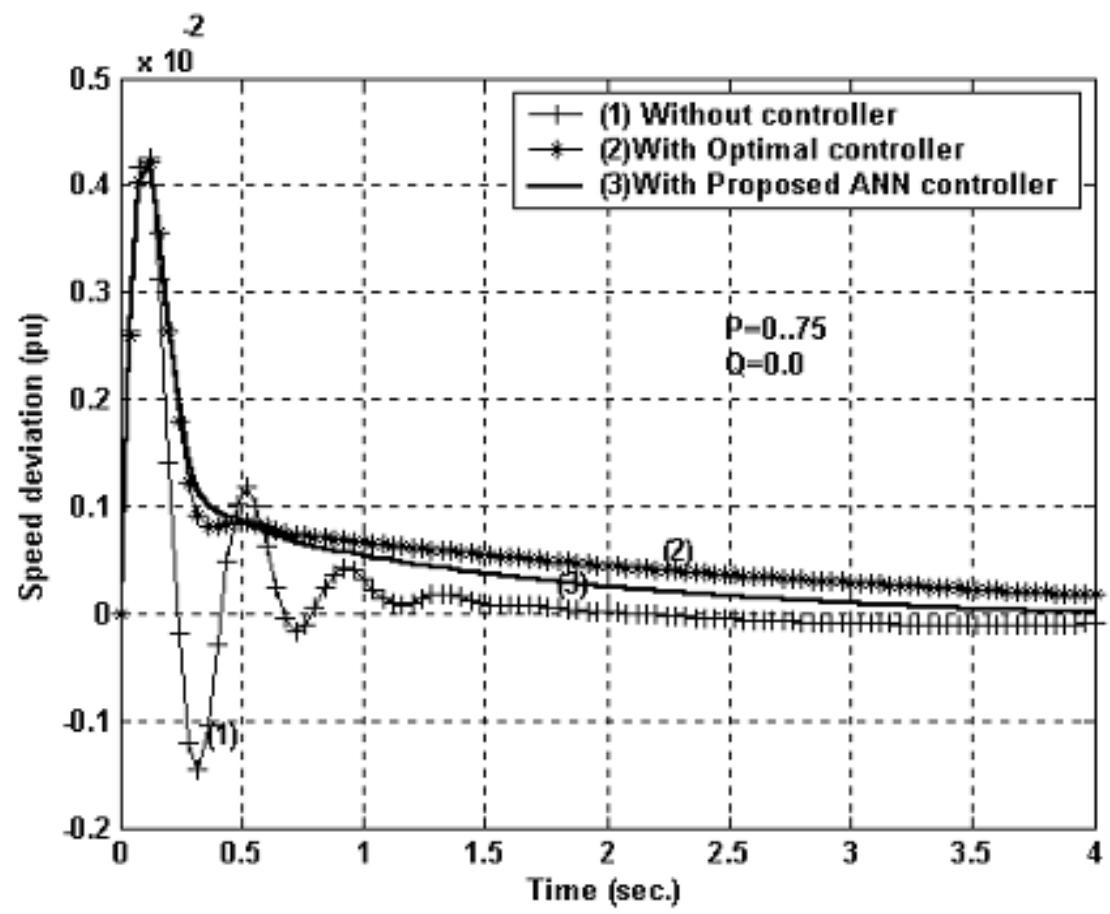

Fig. 6: Rotor speed deviation response due to $0.01 \mathrm{pu}$ load disturbance at loading condition ( $P=0.75 Q=0.0)$.

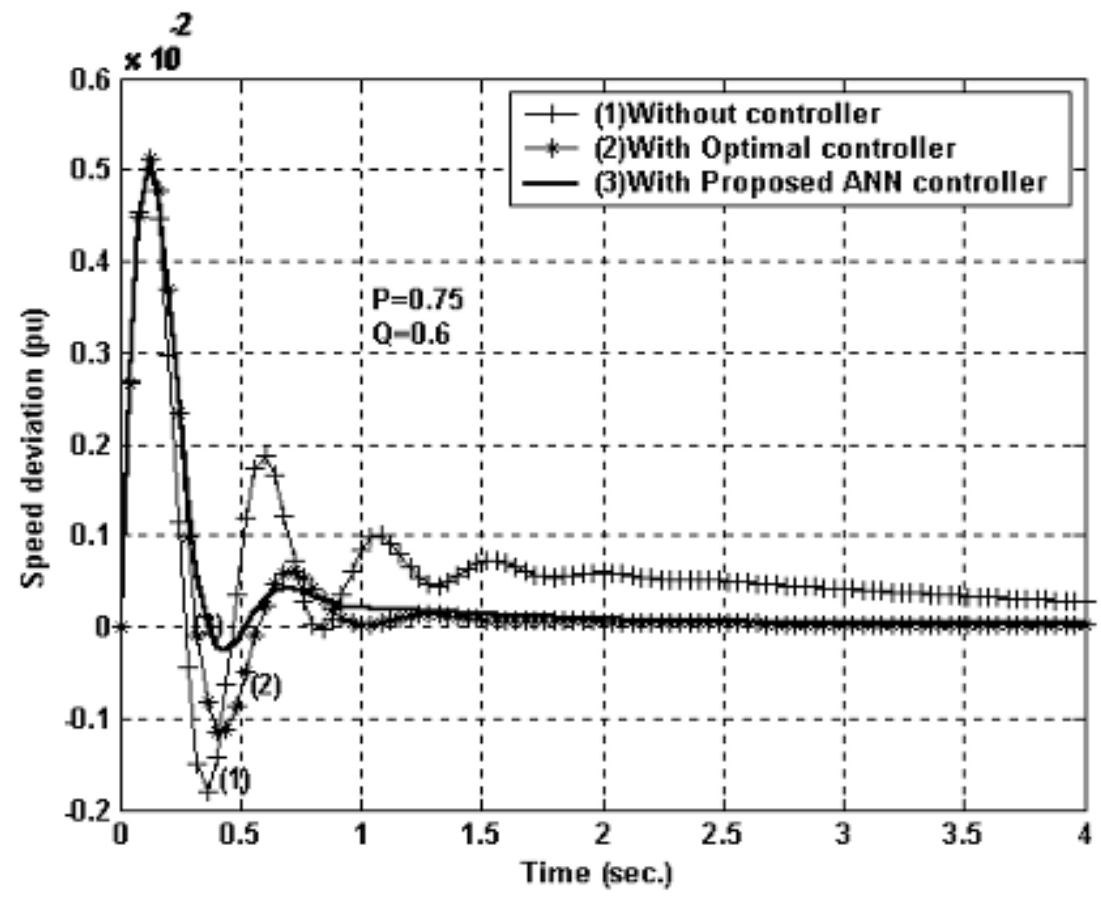

Fig. 7 : Rotor speed deviation response due to 0.01 pu load disturbance at loading condition $(\mathrm{P}=0.75 \mathrm{Q}=0.6)$. 


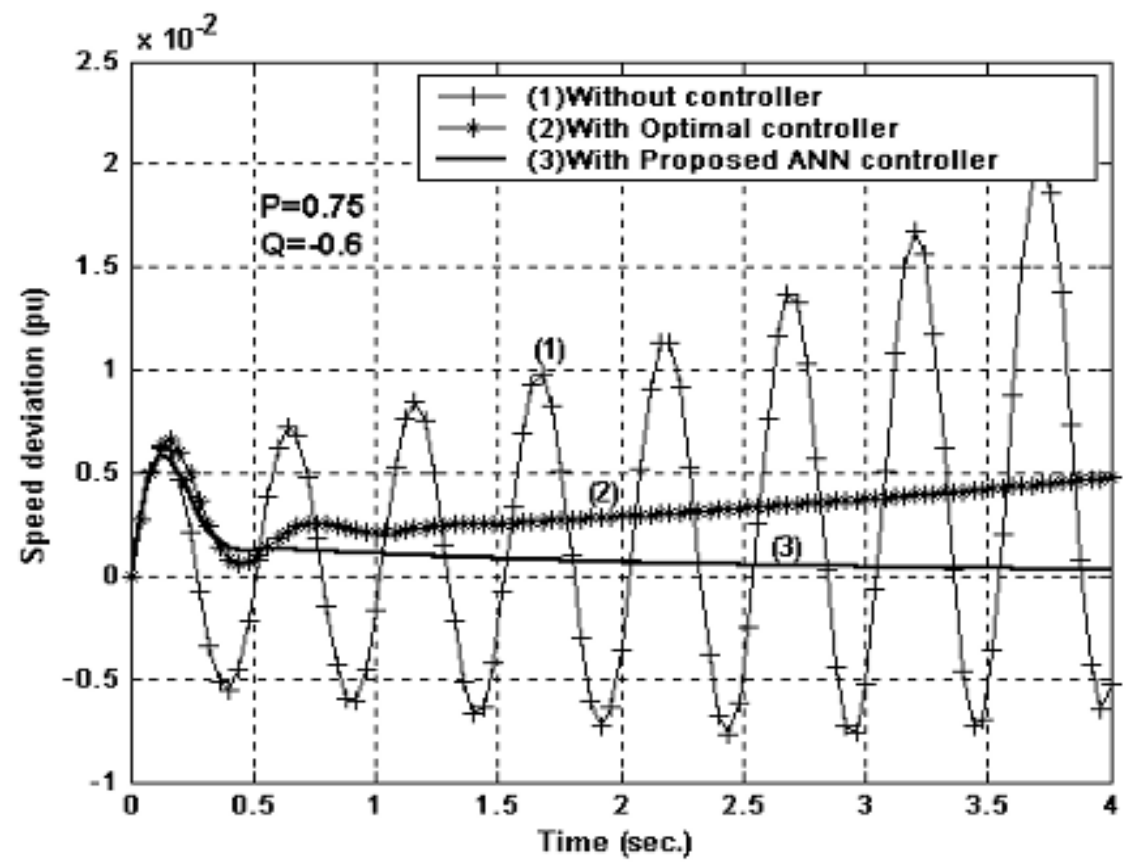

Fig. 8 : Rotor speed deviation response due to $0.01 \mathrm{pu}$ load disturbance at different controller at loading condition ( $P=0.75 Q=-0.6)$.

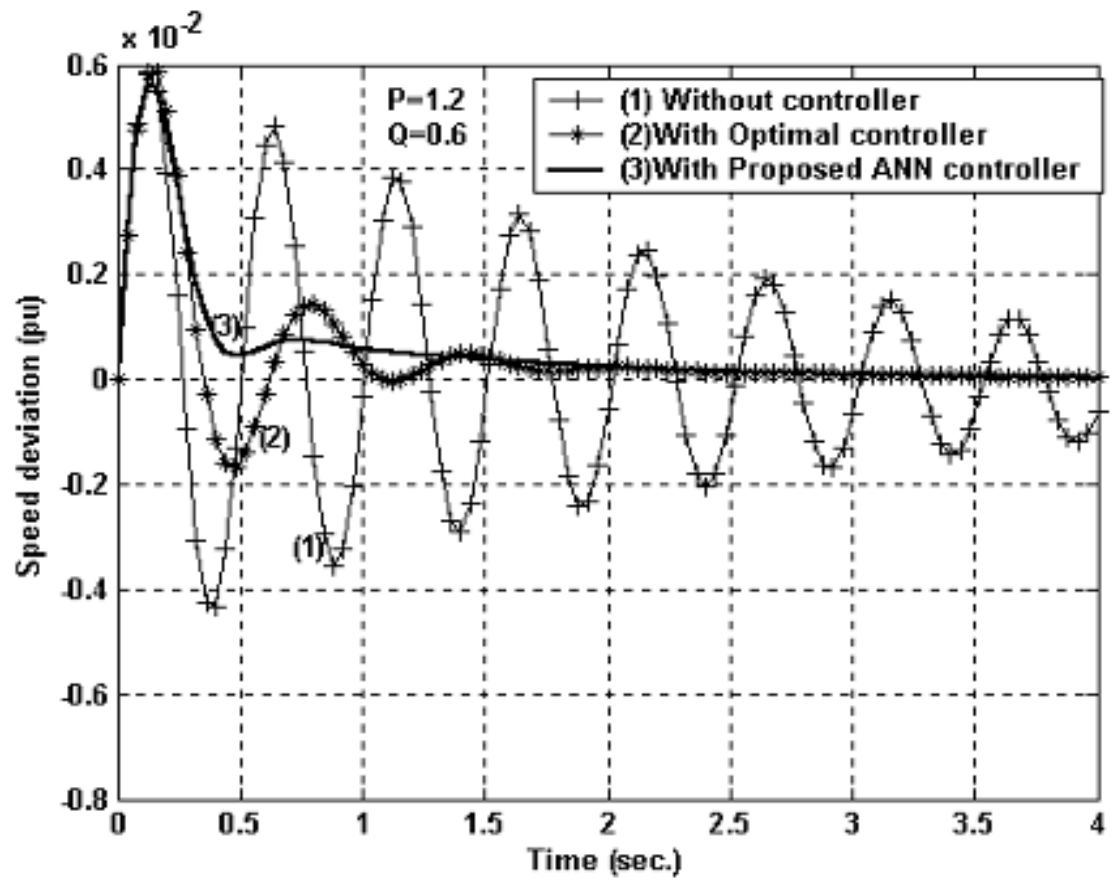

Fig. 9: Rotor speed deviation response due to 0.01 pu load disturbance at loading condition $(P=1.2 \mathrm{Q}=0.6)$. 


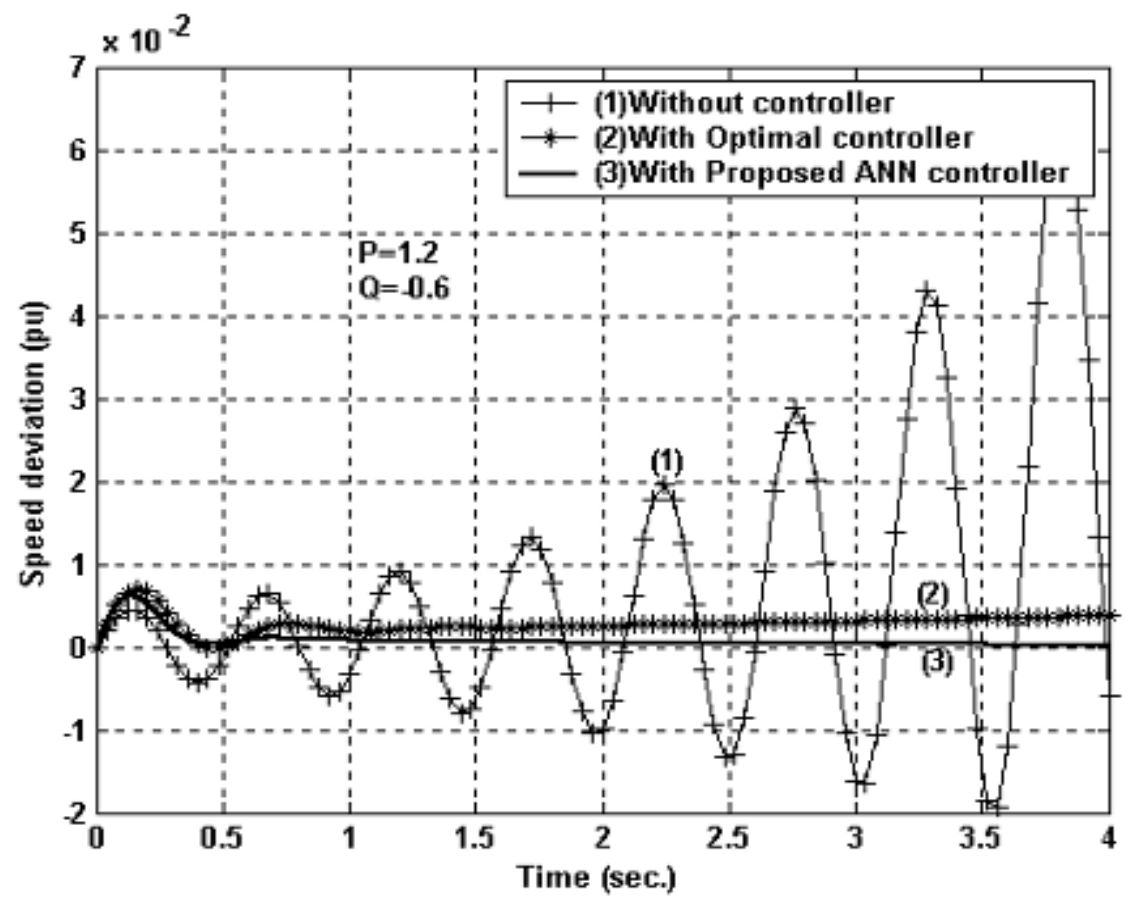

Fig. 10: Rotor speed deviation response due to 0.01 pu load disturbance at loading condition $(\mathrm{P}=1.2 \mathrm{Q}=-0.6)$.

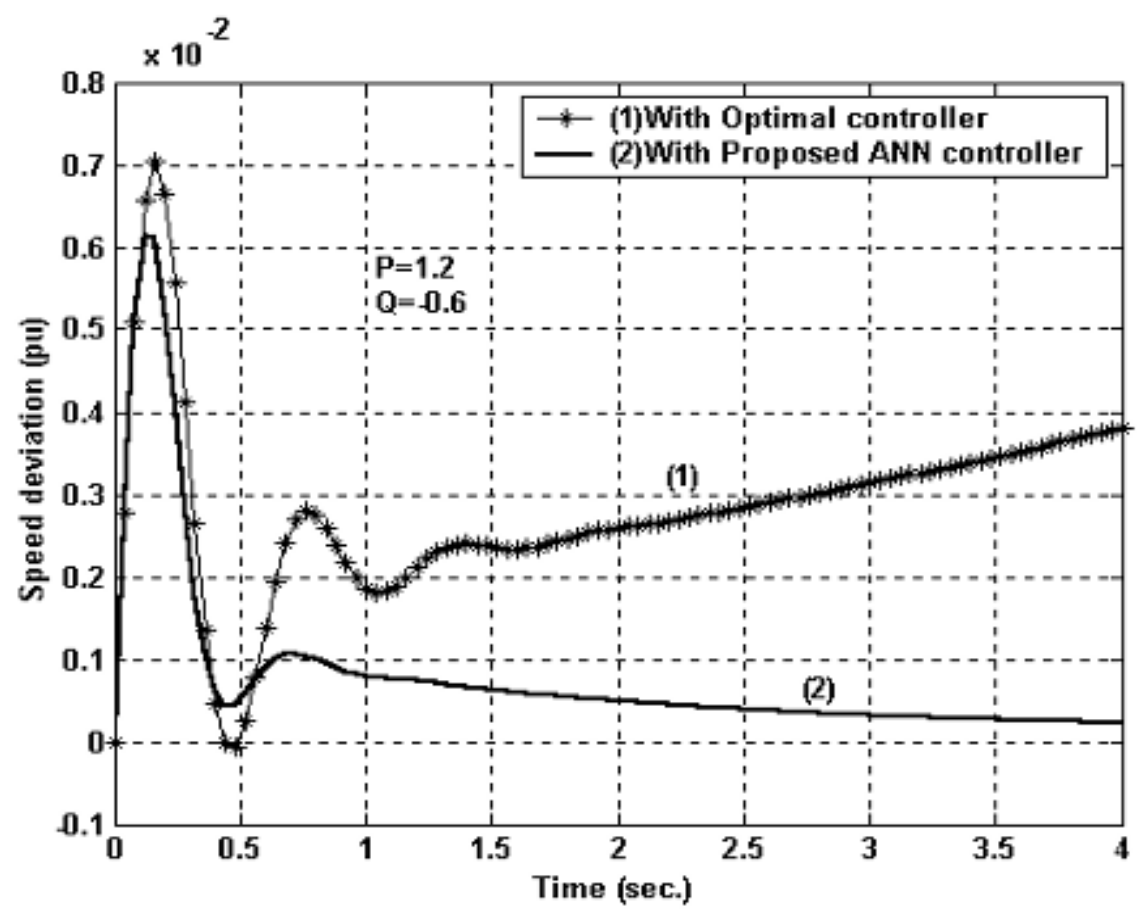

Fig. 11: Rotor speed deviation response due to $0.01 \mathrm{pu}$ load disturbance at loading condition( $\mathrm{P}=1.2 \mathrm{Q}=-0.6)$. 
Table 3: Settling time of different cases at different loading condition.

\begin{tabular}{|c|c|c|c|}
\hline $\begin{array}{l}\text { Loading } \\
\text { condition }\end{array}$ & Without controller & $\begin{array}{l}\text { With optimal } \\
\text { controller }\end{array}$ & $\begin{array}{l}\text { With proposed } \\
\text { ANN controller }\end{array}$ \\
\hline $\mathrm{P}=0.25 \quad \mathrm{Q}=0.0$ & $6 \mathrm{Sec}$. & $1.5 \mathrm{Sec}$. & $1.2 \mathrm{Sec}$ \\
\hline $\mathrm{P}=0.75 \quad \mathrm{Q}=0.6$ & 7 Sec. & 3 Sec. & $1.4 \mathrm{Sec}$. \\
\hline $\mathrm{P}=0.75 \quad \mathrm{Q}=-0.6$ & $\infty$ Sec. & $\infty$ Sec. & $3.5 \mathrm{Sec}$. \\
\hline
\end{tabular}

\section{CONCLUSION}

An optimal artificial neural network controller has been developed to be included in power systems in order to improve the dynamic response of this system and to give an optimal performance at any loading condition. The proposed controller has ability to adapt its parameters at any loading condition. This controller is designed based on reduced order model of power system in order to retain only the states, which are measurable or observable. The feature of this controller is the reduction of the consuming time and reduction of the number of neurons, which are required for proposed ANN structure. The obtained results show the effectiveness of proposed ANN controller in enhancing the damping characteristic of the studied power system at any loading condition in comparison with optimal feedback controllers. The proposed controller has better perfoprmance than the optimal feedback controller in terms of fast damping response and small settling time .

\section{REFERENCES}

[1] E. J. Davison, "A Method for Simplifying Linear Dynamic Systems", IEEE Trans., Vol.AC-11, No.1, pp.93-99, January 1966.

[2] A. Kuppurajulu and S. Elangovan, "Simplified Power System Models for Dynamic Stability Studies”, IEEE Trans., Vol.PAS-90, No.1, pp.11-25 January/ February 1971.

[3] M. J. Gibbared, " Coordinated Design of Multi-Machine Power System Stabilizer based on Damping Torque Concept", IEE Proc. C. 135(4), (1988), 276-284.

[4] A. B. R. Kumar and E. F. Richards, "An Optimal Control Law by Eigenvalue Assignment for Improved Dynamic Stability in Power Systems”, IEEE Trans., Vol.PAS-101, No.6, pp.1570-1577, 1982.

[5] O. A. Solheim, "Design of Optimal Control Systems with Prescribed Eigenvalues”, Int. J. Control, Vol.15. No.1, pp.143-150, 1972.

[6] Dejan J. S. and Y. H. Pao, "Artificial Neural-Net Based Dynamic Security Assessment for Electric Power Systems", IEEE PWRS, Vol.4, No.1, February 1991.

[7] Y. Y. Hsu and C. R. Chen, "Tuning of Power System Stabilizer using Neural Network Approach", IEEE Trans. On Energy Conversion, Vol.6, No.4, 1991.

[8] Zhang, et al, "An Artificial Neural Network Based Adaptive Power System Stabilizer", EEE Trans. On Energy Conversion, Vol. 8, March 1996.

[9] M. K. El-Sherbiny, et al, "Speed Deviation Adaptive Neural Network Based Power System Stabilizer", EPSR Journal, Vol. 38, pp.169-175, 1996. 
[10] L. C. Min and L. Qing, "An enhanced Adaptive Neural Network Control Scheme for Power Systems", IEEE Trans. On Energy Conversion, Vol. 12, No. 2, pp.166-174, 1997.

[11] A. M. Abdel Hamid, M. T. Sayed, Al-Sayed A. Sallam and A. M. EL Mogy, "A Comparison Between Nonlinear Optimal Controller and Neural Network Controller for Robotics", MEPCON'2003, Electrical Engineering Department, Faculty of Engineering, Monoufiya University, Shebin El-kom, Egypt, pp.291301, December 2003.

[12] El-Noby A. Ibrahime "An Optimal pole Shifting multi-input Fuzzy Logic Controller for Reduced Order Power Systems", Journal of Engineering Science, Assiut University, Vol.33 No. 3, May 2005.

\section{APPENDICES}

\section{Appendix-a : Elements definition of A-matrix}

$$
\begin{aligned}
& \psi_{d 0}=-x_{d} I_{d 0}+x_{m d} I_{f 0} \\
& \psi_{q 0}=x_{q} I_{q 0} \\
& M 10,1=\frac{K_{r} V_{q 0} r_{l}-K_{r} V_{d 0} x_{l}}{T_{r} V_{t 0}} \\
& M 10,2=\frac{K_{r} V_{q 0} x_{l}-K_{r} V_{d 0} r_{l}}{T_{r} V_{t 0}} \\
& M 10,6=\frac{K_{r} V_{q 0} V_{b} \sin \delta_{0}+K_{r} V_{d 0} V_{b} \cos \delta_{0}}{T_{r} V_{t 0}} \\
& M 10,7=\frac{K_{r} V_{q 0} I_{d 0} x_{l}-K_{r} V_{d 0} I_{q 0} x_{l}}{T_{r} V_{t 0}} \\
& \psi_{d 0}=-x_{d} I_{d 0}+x_{m d} I_{f 0} \\
& \psi_{q 0}=x_{q} I_{q 0} \\
& M 10,1=\frac{K_{r} V_{q 0} r_{l}-K_{r} V_{d 0} x_{l}}{T_{r} V_{t 0}} \\
& M 10,2=\frac{K_{r} V_{q 0} x_{l}-K_{r} V_{d 0} r_{l}}{T_{r} V_{t 0}} \\
& M 10,6=\frac{K_{r} V_{q 0} V_{b} \sin \delta_{0}+K_{r} V_{d 0} V_{b} \cos \delta_{0}}{T_{r} V_{t 0}} \\
& M 10,7=\frac{K_{r} V_{q 0} I_{d 0} x_{l}-K_{r} V_{d 0} I_{q 0} x_{l}}{T_{r} V_{t 0}}
\end{aligned}
$$




\section{Appendix-b :System parameters}

Table b-1: parameter of one machine -infinite bus( in per unit).

\begin{tabular}{|l|c|c|c|}
\hline $\mathbf{x}_{\mathbf{q}}$ & 1.563 & $\boldsymbol{\omega}_{\mathbf{b}}$ & 377 \\
\hline $\mathbf{x}_{\mathbf{d}}$ & 1.653 & $\mathbf{M}$ & 00.014 \\
\hline $\mathbf{x}_{\mathbf{m q}}$ & 1.47 & $\mathbf{D}$ & 0.0 \\
\hline $\mathbf{x}_{\mathbf{m d}}$ & 1.56 & $\mathbf{R}_{\mathbf{g}}$ & 18.85 \\
\hline $\mathbf{x}_{\mathbf{k q}}$ & 1.503 & $\mathbf{T}_{\mathbf{g}}$ & 0.25 \\
\hline $\mathbf{x}_{\mathbf{k d}}$ & 1.608 & $\mathbf{T}_{\mathbf{t}}$ & 1 \\
\hline $\mathbf{x}_{\mathbf{f d}}$ & 1.646 & $\mathbf{K}_{\mathbf{e}}$ & 13.89 \\
\hline $\mathbf{x}_{\mathbf{I}}$ & 0.2 & $\mathbf{K}_{\mathbf{a}}$ & 50 \\
\hline $\mathbf{r}_{\mathbf{a}}$ & 0.0032 & $\mathbf{K}_{\mathbf{r}}$ & 1 \\
\hline $\mathbf{r}_{\mathbf{f d}}$ & 0.001 & $\mathbf{K}_{\mathbf{s}}$ & 0.057 \\
\hline $\mathbf{r}_{\mathbf{k d}}$ & 00.011 & $\mathbf{T}_{\mathbf{e}}$ & 0.28 \\
\hline $\mathbf{r}_{\mathbf{k q}}$ & 00.014 & $\mathbf{T}_{\mathbf{a}}$ & 0.02 \\
\hline $\mathbf{r}_{\mathbf{l}}$ & 0.02 & $\mathbf{T}_{\mathbf{r}}$ & 0.001 \\
\hline $\mathbf{V}_{\mathbf{b}}$ & 1 & $\mathbf{T}_{\mathbf{s}}$ & 0.45 \\
\hline
\end{tabular}

\section{منظم شبكات الأكاء الاصطناعي ذو الأداء الأمثل لمنظومة القوى الكهربية المقترحة الرتبه الأبهائ}

المقالة تعرض منظم شبكات الذكاء الاصطناعي ذو الأداء الأمثل لمنظومة القوى الكهربية

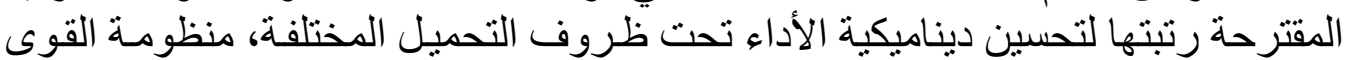

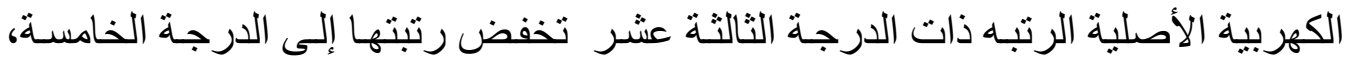

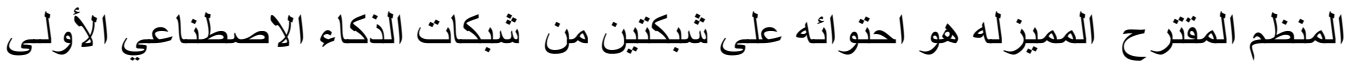

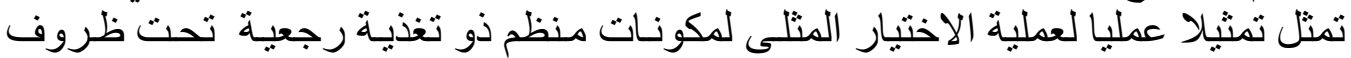
التحميل المختلفة الثانية تمثل تمثيلا عمليا للمنظم الأمثل وذلك لانتاج إثـارة التحكم، شبكة فيكة

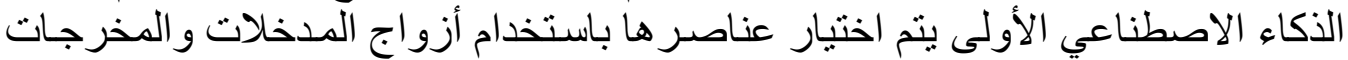

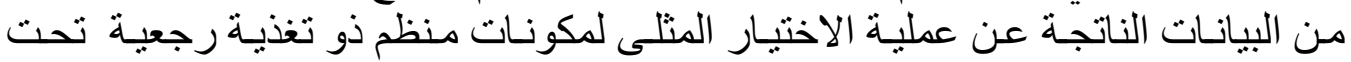

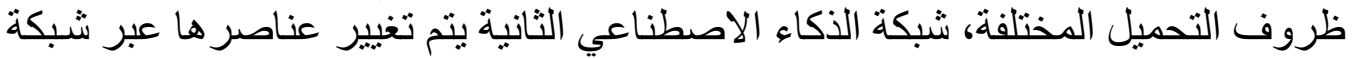

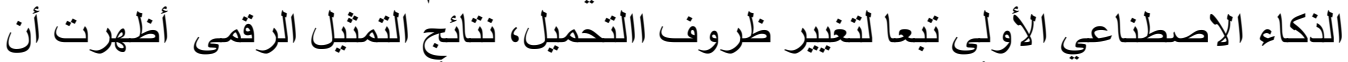

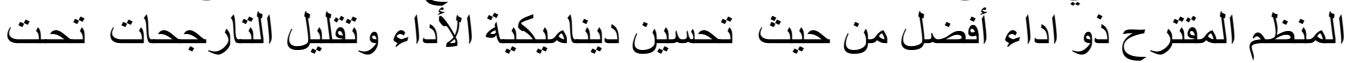
ظروف التشغيل المختلفة وكذلك فاعليته و اعتماديته بالمقارنة بالمنظمات الأخرى. 